\title{
The Effect of Organizational Quality Specific Immune on Innovation Performance in Manufacturing Enterprises
}

\author{
Zhifeng Lian ${ }^{1, *}$, Qiang Liu², Yu Guo ${ }^{3}$ \\ 1School of Economics, Liaoning University of Technology, Jinzhou, Liaoning, China \\ 2School of Management, Liaoning University of Technology, Jinzhou, Liaoning, China \\ 3School of Economics and Management, Harbin Engineering University, Heilongjiang, China
}

Keywords: Innovation Performance, Organizational Quality Specific Immune, Fuzzy Set Qualitative Comparison Analysis

Abstract: Based on the coordination of research issues of organizational quality specific Immune and innovation performance through literature research, this study uses fuzzy set qualitative comparative analysis to evaluate the innovation performance based on product innovation and process innovation from the perspective of organizational quality specific immune. Based on the idea of membership degree, the quantitative components such as comprehensive evaluation value and clustering are added to process the data, finally three paths affecting innovation performance are obtained from the perspective of organizational quality specific immune.

\section{Introduction}

Innovation affects the survival state of enterprises, and quality is the key to enterprise survival. The pursuit of innovation performance in order to improve the survival status of enterprises results in the quality of enterprises being threatened by various pathogens such as competitors, suppliers and consumers. The failure of phagocyte to timely carry out non-specific phagocytes leads to the failure of product innovation due to the poor quality of raw materials, the defects in organizational monitoring leads to shoddy products, imperfect organizational defense makes product quality unable to resist macroeconomic policy changes and the threats by other enterprises in the same industry, the decline of organizational memory ability cannot timely follow up the technological frontier and affect technological innovation. Therefore, it is of practical significance to study the relationships among quality and product innovation and technological innovation. The purposes of new product development, innovation development technology and management concept are to create good development environment for manufacturing enterprises, improve enterprise performance and achieve sustainable development. Due to that the organizational quality specific immune is lack and imperfect, which causes the good vision to come to nothing. As for antibody and antigen in biological immune responses of internal and external risk adjustment process, Wang and other scholars try to introduce biological immunity to the organization and enterprise for the 
first time ${ }^{[1]}$, Shi and others combine organizational immune theory with quality management ${ }^{[2-4]}$, Chen et al. apply immune theory into the scope of enterprise performance study ${ }^{[5]}$. Although some scholars apply immune theory to quality management, only a handful of scholars make empirical analysis combining immune theory with quality management. Moreover, the related study projects on the relationships between organizational quality specific immune and innovation performance are relatively rack. Yu focuses on the study of technological innovation risk management on innovation performance by emphasizing on enterprise technological innovation ${ }^{[6]}$. Zhao et al. adopt fsQCA to focus on the improvement path of diverse performances ${ }^{[7]}$. Liu et al. study on the innovation performance from the perspective of innovation achievements that increase enterprise value. Based on marketing ability ${ }^{[8]}$, Li studies on the influence of marketing ability on innovation performance $^{[9]}$. Li et al. study on the related contents of innovation performance by Bootstrap software from the perspective of open innovation ${ }^{[10]}$. Wang studies on the innovation performance of enterprises based on the relationships between the two parties ${ }^{[11]}$. Fang et al. apply visual softwares of CiteSpaceIII and SATI3.2 to carry out the research of the influence of leadership on innovation performance ${ }^{[12]}$.

\section{Definition and Connotation of the Concept}

This section provides the following theoretical basis for the study.

\subsection{Organizational Quality Specific Immune}

Wang et al. first propose the combination of biological immune theory and enterprise organization practice $^{[1]}$. Wang believes that the application of the immune system can enhance the immunity of enterprises and foster the promotion and stability of various benefits of enterprise ${ }^{[13]}$. Pan et al. summarize the immune theory ${ }^{[14]}$. Li et al. compare the prevention system of enterprises with the biological immunity, and discuss the immunity of organizational quality from the perspective of immunology ${ }^{[15]}$. Lv et al. ${ }^{[16]}$ and Jiang et al. ${ }^{[17]}$ both mention that the organizational immune system is composed of three aspects. Xie et al. indicate that there are also innate non-specific immunity and acquired specific immunity in the immune system of enterprises ${ }^{[18]}$. Therefore, organizational immune can be divided into organizational non-specific immune and organizational specific immune. And organizational quality specific immune is an extension of organizational specific immune, which transfers the subject of immune theory from biology to enterprise quality. Organizational quality specific immune is composed of organizational quality monitoring, organizational quality defense and organizational quality memory.

Organizational quality monitoring is to timely perceive the quality environment, find the existing problems and eliminate the threat in the embryonic stage, and reduce the quality cost by enterprise. Organizational quality defense is a process in which the enterprise actively or passively changes the supply strategy, adjusts the resource allocation, coordinates the production pace and so on to deal with quality problems. Organizational quality memory is the key for an enterprise to deal with risks successfully. It is the summary of the records of organizational quality monitoring and organizational quality defense, and which conducts feedback to organizational quality monitoring and organizational quality defense.

\subsection{Innovation Performance}

Zhao et al. believe that innovation performance is to enhance enterprise value through technological innovation $^{[19]}$. Yang et al. indicate that innovation performance refers to the effect of product output in the process of product or process innovation ${ }^{[20]}$. Yang finds out that innovation results from innovation activities are innovation performance ${ }^{[21]}$. Innovation performance refers to the 
improvement of the overall performance of the enterprise through a series of innovative activities, which is manifested in the improvement of economic benefits and the increase of social benefits, such as sales, net profit, patent technology and so on. Innovation performance is classified into technological innovation, organizational innovation, product innovation and process innovation by category $^{\text {[22-24] }}$. In terms of organizational quality of manufacturing enterprises, technological innovation can lead to product innovation, and further process innovation includes new processes and new organizational management methods. Therefore, this study divides the evaluation indexes of innovation performance into product innovation and process innovation by enterprises.

\section{Model Construction}

This section provides evaluation index systems, research assumptions and conceptual model.

\subsection{Evaluation Index System}

Based on the research outcomes on innovation performance ${ }^{[7-12,25]}$, summarize and get index system of innovation performance from related research, as shown in table 1.

Table 1: Innovation performance evaluation index system.

\begin{tabular}{|c|c|c|}
\hline Evaluation goal & Construction dimension & Evaluation indicator \\
\hline \multirow{10}{*}{ Innovation performance (CXJX) } & \multirow{5}{*}{ Product innovation (CPCX) } & Number of new products (CP1) \\
\hline & & Speed of development of new products(CP2) \\
\hline & & Differences between new products (CP3) \\
\hline & & Market recognition of new products (CP4) \\
\hline & & Market response for new products (CP5) \\
\hline & \multirow{5}{*}{ Process innovation (GPCX) } & Market response for new products (GP1) \\
\hline & & Improvement of production equipment (GP2) \\
\hline & & Qualified rate of new products (GP3) \\
\hline & & Production efficiency of new products (GP4) \\
\hline & & Change in production management system (GP5) \\
\hline
\end{tabular}

Specific immune is mostly used in medical research, such as the prevention and treatment of diseases of human or animal immune function and biological significance. Organizational quality specific immune by enterprise consists of organizational quality monitoring, organizational quality defense and organizational quality memory ${ }^{[1]}$. Combined with the study of quality specific immunity by relevant scholars ${ }^{[1-5,13-18,26-33]}$, the evaluation index system of organizational quality specific immune is summarized as shown in table 2.

Table 2: Organizational quality specific immune evaluation indicator system.

\begin{tabular}{|c|c|c|}
\hline \multicolumn{2}{|c|}{ Construction dimension } & Evaluation indicator \\
\hline \multirow{6}{*}{\multicolumn{2}{|c|}{ Organization quality monitoring (JS) }} & Organization quality external environment monitoring (JS1) \\
\hline & & Organizational quality internal environmental monitoring (JS2) \\
\hline & & Organization of quality internal activity monitoring (JS3) \\
\hline & & Value judgment (JS4) \\
\hline & & Cognitive motivation (JS5) \\
\hline & & Cognitive diversity (JS6) \\
\hline \multirow{7}{*}{$\begin{array}{l}\text { Organization quality } \\
\text { defense (FY) }\end{array}$} & \multirow{4}{*}{$\begin{array}{l}\text { Soft elements of organizational } \\
\text { quality defense }\end{array}$} & Leadership's focus on organizational quality (FY1) \\
\hline & & Frequency of staff participation (FY2) \\
\hline & & Relationship management among suppliers (FY3) \\
\hline & & Level of focus on customer needs (FY4) \\
\hline & \multirow{3}{*}{$\begin{array}{c}\text { Hard elements of organizational } \\
\text { quality defense }\end{array}$} & Products design (FY5) \\
\hline & & Process management (FY6) \\
\hline & & Statistical control and feedback (FY7) \\
\hline \multirow{2}{*}{\multicolumn{2}{|c|}{ Organization quality memory (JY) }} & Studying (JY1) \\
\hline & & Recording (JY2) \\
\hline
\end{tabular}




\begin{tabular}{|l|c|}
\hline \multirow{4}{*}{} & Summing up (JY3) \\
\cline { 2 - 2 } & Saving (JY4) \\
\cline { 2 - 2 } & Dissemination and diffusion (JY5) \\
\cline { 2 - 2 } & Communication control and supervision (JY6) \\
\hline
\end{tabular}

\subsection{Research Hypothesis}

Organizational quality monitoring can identify the factors that threaten product quality in the first time and request organizational quality defense to deal with them. Effective organization quality monitoring can block pathogens before production operation, ensure the normal operation of enterprises, and also ensure the innovation activities of enterprises. Organizational quality monitoring can monitor factors that affect innovation activities, conduct the market recognition of new products before product innovation, compare the competitive advantages of new products in the same industry, judge the acceptance of the management system within the enterprise, monitor the application of new technology in products. The following assumptions are made:

H1: Organizational quality monitoring affects innovation performance (JS).

Organization quality defense is the core process of organization quality specific immunity and also the core link of enterprise quality management department. The treatment of disharmony factors of product quality is not only related to whether products can enter the market and be accepted by consumers, but also related to the improvement of enterprise competitiveness. Review of product quality when new products fail to gain a foothold in the market, examine the application of new technologies in related fields if new technologies and products are not well integrated after technological innovation, verify the operation of new equipment. The following assumptions are made:

H2: Organizational quality defense affects innovation performance (FY).

Organizational specific immune is the key to directly to organizational defense by organizational memory. For example, the solution of product consumer policies and other obstacles encountered in innovation activities can be summarized. When enterprises encounter similar problems in similar innovation activities again, they can directly refer to the summary to deal with them. At the same time, by shortening the time to identify antigens, it can reduce the processing time of organizational quality defense to various factors affecting innovation activities, which is conducive to enterprises to quickly occupy the market to obtain support, form a competitive advantage, and thus increase enterprise performance. The following assumptions are made:

H3: Organizational quality memory affects innovation performance (JY).

\subsection{Conceptual Model}

According to the established evaluation index system and the proposed study hypothesis, a conceptual model of the impact of organizational quality specific immune on innovation performance in manufacturing enterprises is constructed. The specific conceptual model is shown in figure 1. 


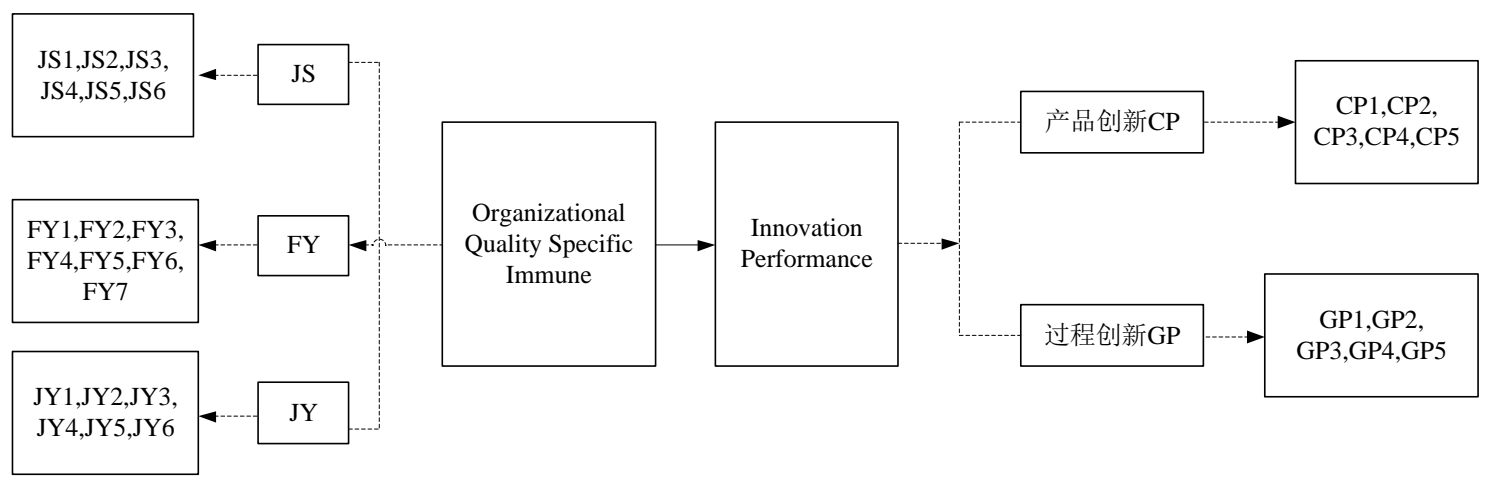

Figure 1: Conceptual model.

\section{Empirical Analysis and Results}

This section provides empirical analysis processes and results.

\subsection{Empirical Analysis Method Selection}

Choosing G1 method and entropy method to calculate weights to deal with innovation performance data. G1 method for weighting: the standardized data is obtained according to formula (1), then calculate the normalized data according to formula (2) to obtain the weight.

$$
\begin{aligned}
& x^{\prime}=\frac{x-x_{\min }}{x_{\max }-x_{\min }} \\
& w_{m}=\left(1+\sum_{k=2}^{m} \Pi_{r_{k}}\right)^{-1}
\end{aligned}
$$

Entropy method for weighting: calculate the entropy value according to formula (3) and (4).

$$
\begin{gathered}
f_{i j}=\frac{x_{i j}}{\sum_{i=1}^{n} x_{i j}} \\
e_{j}=-\frac{1}{\ln n} \sum_{i=1}^{n} f_{i j} \ln \left(f_{i j}\right)
\end{gathered}
$$

Calculate the entropy weight according to formula (5).

$$
w_{k}=\frac{1-e_{j}}{n-\sum_{i=1}^{n} e_{i}}
$$

The G1 method weights and entropy value method weights are brought into formulas (6) and (7).

$$
\begin{gathered}
\alpha=\frac{\sum_{i=1}^{n} \sum_{k=1}^{m} x_{k i}{ }^{2} w_{k}\left(w_{k}+\rho_{k}\right)}{\sum_{i=1}^{n} \sum_{k=1}^{m} x_{k i}{ }^{2}\left(w_{k}+\rho_{k}\right)^{2}} \\
\beta=\frac{\sum_{i=1}^{n} \sum_{k=1}^{m} x_{k i}{ }^{2} \rho_{k}\left(w_{k}+\rho_{k}\right)}{\sum_{i=1}^{n} \sum_{k=1}^{m} x_{k i}{ }^{2}\left(w_{k}+\rho_{k}\right)^{2}}
\end{gathered}
$$

After entering the formula, the combined weight coefficient is calculated. The combination weight coefficient is brought into formula (8) to obtain the combination weight. 


$$
\mu_{k}=\alpha \rho_{k}+\beta w_{k}
$$

Catastrophe progression method. Although the catastrophe progression method does not be involve in weighting, it takes into account the relative importance of each indicator. It not only avoids the shortcomings of weighting, but also can apply multi-dimensional fuzzy membership to the normalization of multi-layer indicators. Since there are no obvious boundaries between the various levels of tissue quality specific indicators, organizational quality monitoring, organizational quality defense and organizational quality memory are complementary, so the catastrophe progression method is used to statically evaluate the relevant data after standardization.

Qualitative comparative analysis of fuzzy sets (fsQCA). The qualitative comparative analysis of fuzzy sets is a method of analyzing the relationship between the combination of results and conditional sets. As the innovation performance researched in this article, the formation of high innovation performance must be a combination of a combination of various factors. After Charles C. Ragin conducted qualitative comparative analysis of fuzzy sets and developed fsQCA software, domestic scholars have also conducted related research and extended the method to the study of enterprise performance. However, most scholars still take case analysis, the sample size is small, and coding is performed directly. Although the follow-up scholars use small groups to discuss coding or multi-person coding in the study to reduce the subjectivity of coding, this method is only applicable to the sample size In rare cases, when the sample size is enough, the original coding method is time-consuming and labor-intensive. Therefore, based on the research on fsQCA, this study adds to the process of calculating the comprehensive evaluation value and classification, and the membership in fsQCA. The idea of increasing the degree of quantization makes it easy to process large sample data.

\subsection{Data Collection and Processing}

This section provides data collection and processing.

\subsubsection{Data Collection}

According to the designed questionnaire, the main form of the questionnaire is 1-7 scoring. The questionnaire includes four parts: basic information, innovation performance, quality specific immunity of manufacturing enterprises and open questions. After the first draft of the questionnaire is drawn up according to the research content, the relevant professionals are discussed, the problems irrelevant to this study content are eliminated and the guiding problems are modified. The preliminary revised questionnaire is submitted to the middle and basic level managers of the manufacturing enterprises for trial filling. According to the opinion when filling in, delete the question of "gender" and "age", combine "whether it is middle management" and "whether it is grass-roots management" to form a formal questionnaire.

After the formal survey begins, check the total number of recovered questionnaires, check the details of questionnaire question 1 "What is the name of your company" on an irregular basis, and grasp the number of valid questionnaires recovered from each manufacturing enterprise. Delete the link sent in the manufacturing enterprise when the valid questionnaire reaches an acceptable quantity. When the number of enterprises is obviously insufficient, the questionnaire is redistributed. This study estimates that each manufacturing enterprise recovers 3-6 valid questionnaires, actually a total of 276 questionnaires and a total of valid 214 questionnaires.

\subsubsection{Data Processing}

After the designed questionnaire passed the reliability and validity test, the original data collected was standardized according to formula (1). 
The comprehensive evaluation value of innovation performance is obtained by the optimal combination weight. Based on expert advice, CP1-CP5 and GP1-GP5 of product innovation and process innovation under innovation performance are weighted. G1 method and entropy method are used to calculate the weight respectively, and then the combined weight is calculated to obtain the evaluation value. The calculated combined weights are shown in table 3.

Table 3: Calculation results of combined weight.

\begin{tabular}{|c|c|c|c|c|c|c|c|c|c|c|}
\hline index & CP1 & CP2 & CP3 & CP4 & CP5 & GP1 & GP2 & GP3 & GP4 & GP5 \\
\hline G1 weight $\rho_{k}$ & 0.1527 & 0.1174 & 0.0978 & 0.0816 & 0.0742 & 0.1285 & 0.1071 & 0.0974 & 0.0749 & 0.0681 \\
\hline Entropy & 0.9699 & 0.9785 & 0.9797 & 0.9763 & 0.9732 & 0.9777 & 0.9755 & 0.9790 & 0.9771 & 0.9775 \\
\hline Entropy weight $w_{k}$ & 0.1276 & 0.0913 & 0.0861 & 0.1005 & 0.1140 & 0.0945 & 0.1040 & 0.0892 & 0.0972 & 0.0955 \\
\hline Combination weight $\mu_{k}$ & 0.1401 & 0.1043 & 0.0919 & 0.0911 & 0.0942 & 0.1056 & 0.1114 & 0.0932 & 0.0862 & 0.0819 \\
\hline
\end{tabular}

Catastrophe progression method is used to evaluate the organizational quality monitoring, defense and memory under the organizational quality specific immune. Based on the standardized data, the evaluation values of JS, FY and JY are calculated according to the normalization equation.

FsQCA data processing. In this study, the idea of membership degree is added to the quantification component, and the process of calculating the comprehensive evaluation value and classification is added to facilitate the coding of large sample data. Four value assignment methods are selected to encode the data after clustering. SPSS software is used to recode the clustering results of each index into the operation data of fsQCA.

\subsection{Empirical Analysis Process}

The premise of fsQCA analysis is that the combination of conditions is a sufficient and unnecessary condition for the result set. Through the necessity test, fsQCA method can be used for combination analysis, and the necessity test results are shown in table 4 ( indicates that this condition does not exist).

Table 4: Necessity test results.

\begin{tabular}{|l|l|l|}
\hline & Consistency & Coverage \\
\hline js & 0.967475 & 0.773300 \\
\hline$\sim$ js & 0.231095 & 0.472564 \\
\hline fy & 0.972923 & 0.767676 \\
\hline$\sim$ fy & 0.201496 & 0.426213 \\
\hline jy & 0.967638 & 0.785168 \\
\hline$\sim$ jy & 0.238982 & 0.470692 \\
\hline
\end{tabular}

As shown in table 4, the coverage values of JS, $\sim$ JS, FY, FY, JY and $\sim$ JY are all between $0-1$, indicating that these conditional variables can express completely replace innovation performance, and the antecedent conditions pass the necessity test.

Run the fsQCA software for standard analysis to get the result path of conditional configuration that affects innovation performance. The result path is divided into parsimonious parsimonious solution, intermediate solution and complex solution (table 5-7).

Table 5: parsimonious solution of impact conditions of innovation performance.

\begin{tabular}{|c|c|c|c|}
\hline \multicolumn{4}{|c|}{ frequency cutoff: 3.000000} \\
\hline \multicolumn{4}{|c|}{ consistency cutoff: 0.766199 } \\
\hline & raw coverage & unique coverage & consistency \\
\hline & --------- & -------- & 0.773300 \\
\hline js & 0.967474 & 0.000000 & 0.767676 \\
\hline
\end{tabular}




\begin{tabular}{|c|c|c|c|}
\hline jy & 0.967637 & 0.002683 & 0.785167 \\
\hline \multicolumn{4}{|c|}{ solution coverage: 0.991869} \\
\hline & solu & 674 & \\
\hline
\end{tabular}

Table 6: Intermediate solution of impact conditions of innovation performance.

\begin{tabular}{|c|c|c|c|}
\hline \multicolumn{4}{|c|}{ frequency cutoff: 3.000000} \\
\hline \multicolumn{4}{|c|}{ consistency cutoff: 0.766199} \\
\hline & raw coverage & unique coverage & consistency \\
\hline & ---------- & ---------- & ---------- \\
\hline jy & 0.967637 & 0.002683 & 0.785167 \\
\hline fy & 0.972922 & 0.010815 & 0.767676 \\
\hline js & 0.967474 & 0.000000 & 0.773300 \\
\hline \multirow{2}{*}{\multicolumn{4}{|c|}{$\begin{array}{l}\text { solution coverage: } 0.991869 \\
\text { solution consistencv } 0692674\end{array}$}} \\
\hline & & & \\
\hline
\end{tabular}

Table 7: Complex solution of impact conditions of innovation performance.

\begin{tabular}{|c|c|c|c|}
\hline \multicolumn{3}{|c|}{ frequency cutoff: 3.000000} \\
\hline \multicolumn{3}{|c|}{ consistency cutoff: 0.766199} \\
\hline & raw coverage & unique coverage & consistency \\
\hline js & --------------- \\
\hline fy & 0.967474 & -------- & 0.773300 \\
\hline jy & 0.972922 & 0.000000 & 0.767676 \\
\hline \multicolumn{2}{|c|}{ solution coverage: 0.991869} \\
\hline \multicolumn{2}{|c|}{ solution consistency: 0.692674} \\
\hline
\end{tabular}

From table 5, we can see that there are three parsimonious solution, and the consistency scores of both paths are more than 0.75 , which indicates that the interpretation of output variables is good, and the total consistency is more than 0.75 , which indicates that path analysis has the ability to interpret the study results.

\subsection{Empirical Analysis Results}

According to the results of condition reduction path and complex path of the impact of organizational quality monitoring, organizational quality defense and organizational quality memory on innovation performance, with the help of the rules of relevant symbols usage, the configuration combination table of the impact conditions of innovation performance is drawn, and the results are shown in table 8.

Table 8: Configuration combination of impact conditions of innovation performance.

\begin{tabular}{|c|c|c|c|}
\hline \multirow{2}{*}{ variable } & \multicolumn{3}{|c|}{ Innovation performance } \\
\cline { 2 - 4 } & Path 1 & Path 2 & Path 3 \\
\hline Organization quality monitoring (js) & $\bullet$ & $\bullet$ & $\bullet$ \\
\hline Organizational quality defense (fy) & & & 0.767676 \\
\hline Tissue quality memory (jy) & & 0.972922 & 0.967637 \\
\hline consistency & 0.96743300 & 0.010815 & 0.002683 \\
\hline raw coverage & 0.000000 & 0.991869 & \\
\hline unique coverage & \multicolumn{3}{|c|}{0.692674} \\
\hline overall solution coverage & \multicolumn{3}{|c|}{} \\
\hline overall solution consistency & \multicolumn{3}{|c|}{} \\
\hline
\end{tabular}

Note: • $\bullet$ indicates that the condition exists, $\otimes$ and $\otimes$ indicates that the condition does not exist, "blank" indicates that the condition can exist or not exist. $\bullet$ and $\otimes$ indicates the core condition, $\bullet$ and $\otimes$ indicates the auxiliary condition.

Since the simple solution of table 5 impact conditions of innovation performance is the same as the complex solution of table 7 impact conditions of innovation performance, the conditions in the configuration table drawn are the core conditions of this path. As shown in table 8, organizational 
quality monitoring, organizational quality defense and organizational quality memory have three influence paths on innovation performance. Path 1: organizational quality monitoring (JS) affects innovation performance. From table 8 , it can be seen that organizational quality monitoring is the core condition of this path, indicating that as long as organizational quality monitoring exists, whether organizational quality defense and organizational quality memory exist or not, and whether they are auxiliary or not Both assistant conditions and organizational quality monitoring can affect innovation performance. Similarly, both organizational quality defense (FY) and organizational quality memory (JY) can affect innovation performance as a single path.

In the specific configuration path, take path 1 as an example, path 1 means that the manufacturing enterprise's autoimmune system is perfect enough, the enterprise can directly block the factors that threaten the quality outside the production and manufacturing of the enterprise, only need to strengthen the organizational quality monitoring (JS) to ensure the innovation performance of the enterprise. However, the improvement of organizational quality defense (FY) and organizational quality memory (JY) is better Promote the innovation performance of manufacturing enterprises. Through path 2 and path 3, we can see that the higher the degree of organizational quality defense (FY) and organizational quality memory (JY), the more obvious the impact on the innovation performance of manufacturing enterprises. The enhancement of organizational quality defense and organizational quality memory can promote the innovation performance of manufacturing enterprises.

The results of empirical analysis also show that as long as there is specific immunity to organizational quality, no matter whether the path of organizational quality monitoring, defense, memory as a single factor or the path of multiple combinations can have an impact on innovation performance, that is, each path in table 9 can have an impact on Innovation performance.

Table 9: Possible paths affecting innovation performance.

\begin{tabular}{|l|l|l|l|l|l|l|l|l|l|l|l|l|}
\hline & L11 & L12 & L13 & L14 & L21 & L22 & L23 & L24 & L31 & L32 & L33 & L34 \\
\hline JS & $\bullet$ & $\bullet$ & $\bullet$ & $\bullet$ & $\otimes$ & $\otimes$ & $\bullet$ & $\bullet$ & $\otimes$ & $\otimes$ & $\bullet$ & $\bullet$ \\
\hline FY & $\otimes$ & $\otimes$ & $\bullet$ & $\bullet$ & $\bullet$ & $\bullet$ & $\bullet$ & $\bullet$ & $\bullet$ & $\bullet$ & $\otimes$ & $\otimes$ \\
\hline JY & $\bullet$ & $\bullet$ & $\otimes$ & $\otimes$ & $\bullet$ & $\bullet$ & $\otimes$ & $\otimes$ & $\bullet$ & $\bullet$ & $\bullet$ & $\bullet$ \\
\hline
\end{tabular}

\section{Conclusions}

Organizational quality monitoring, organizational quality defense and organizational quality memory are the core conditions of three paths that affect innovation performance. When the autoimmune system of manufacturing enterprises is perfect enough, enterprises can directly exclude the threats that affect innovation performance through organizational quality monitoring. The higher the levels of organizational quality defense and organizational quality memory are, the more obvious the impacts on innovation performance of manufacturing enterprises are. The enhancement of organizational quality memory can promote innovation performance of manufacturing enterprises by expanding the scope of organizational quality monitoring promotion.

(1) Organizational quality monitoring affects innovation performance. When organizational quality monitoring exists, organizational quality monitoring can affect innovation performance (L11-L14) no matter whether organizational quality defense and memory exist or not, no matter what role it plays. The enhancement of organizational quality monitoring can promote innovation performance. In the specific implementation process, through monitoring the internal and external activities, production environment and internal cultural environment of organizational quality, enhance the specific immunity of organizational quality, improve product innovation and process innovation, thus affecting innovation performance: 
(1) Strengthen the monitoring of internal and external activities of the organization, monitor all possible risks, and quickly judge and handle the abnormal situations, so as to affect the innovation performance of the enterprise. Increase the number or times of process inspection, standardize the inspection methods, improve the qualification rate of new products, and ensure the quality of product innovation, promptly return the products identified as "unqualified" to the production station, rework in time, shorten the waiting process outside the storage line, enhance the production efficiency of new products, and further promote product innovation, strengthen the customer requirements for products proposed by the business department to the Engineering Department The review of summation data shall ensure the quality of new products at the source of product research and development. If the machinery and equipment are idle, the maintenance and repair shall be arranged within two weeks to reduce the adverse factors of relevant equipment in the process of research and development and production of new products

(2) Monitor the production environment of the organization, and enhance the innovation performance of the enterprise by reducing the threat of product production. The enterprise can adhere to the consistent monitoring of the external environment, properly strengthen the monitoring of the internal quality environment, and make the quality management departments of the enterprise keep alert at all times. Strengthen the analysis of potential non-conforming factors such as starting natural environment, material specification and performance, production equipment, test instrument function, etc., ensure 1-3 times of analysis before starting each time, ensure the smooth progress of new products or new projects. Ensure the anti-corrosion, insect prevention and other measures in the storage environment, strictly follow the requirements in special environment, at least once a week to avoid the risk of accidents. The lack or imperfection of production environment monitoring affects the production progress of new products, thus promoting the innovation performance of enterprises.

(3) Improve the monitoring of internal cultural environment, affect the innovation performance of enterprises by the innovation of management concept. We should strengthen the supervision over the production management and system of other enterprises in the same industry. In the light of the acceptance of the quality management system and ideas in the enterprises and the business benefits brought by them, we should compare the internal and external environment of the enterprises, quality management systems and ideas, the criteria of value judgment and cognitive diversity, organizational management concepts.

(2) Organizational quality defense affects innovation performance, but the consistency is lower than organizational quality monitoring and organizational quality memory. In the quality management of manufacturing enterprises, the process of dealing with internal and external threats to quality - quality defense plays an important role in quality assurance, which determines the impact of innovation in organizational quality defense on the overall performance improvement of enterprises. In the stage of organizational quality defense, enterprises can improve leaders' emphasis on product this study and development, encourage all employees to participate in new product production, and improve supplier management, which directly affect innovation performance of enterprises.

(1) Strengthen the leadership's emphasis on innovation. Hold product design competition for all employees, pay attention to the cultivation of product design innovation thinking, and enhance innovation performance by increasing the number of product innovation.

(2) Encourage all employees in the company to participate in the supervision of production activities, transfer the supervision of the whole process of product innovation and process innovation from the original supervision department to each employee in the enterprise, provide strong quality supervision for new products from this study and development to production and sales, and guarantee the improvement of innovation performance. 
(3) We should attach importance to the relationship between suppliers strategically and decentralize the power tactically. Quality defense on the supplier side is to solve the quality problems or threats of product innovation at the source. Strategically, we should attach importance to the relationship between suppliers to ensure the quality of raw materials for products. Tactically, we should decentralize the management of suppliers. More suppliers will appear in the list of qualified suppliers. Statistical analysis of the supplier quality monthly report in the past three months, strictly select the appropriate suppliers with guaranteed quality according to the samples and drawings, guarantee the raw material quality of new product production, and eliminate the adverse factors to innovation performance from the root.

(3) Organizational quality memory is one of the ways to affect innovation performance. After the organization quality monitoring and defense, through the summary, filing and dissemination of the organization quality memory, the effective monitoring range and strength of the organization quality monitoring are further enhanced, and the organization defense is enhanced. The organization quality reduces the time for the organization to recognize antigens by increasing the times of eliminating pathogens directly with the organization memory, so as to shorten the period of the organization defense, that is, to shorten the newborn In the trial stage of production process, the running in period of new production equipment is reduced, the production efficiency and qualification rate of new products are improved, and the innovation performance of enterprises is indirectly improved. In the specific implementation process:

(1) Summarize the experience of organization quality monitoring and organization quality defense in time. In the process of product innovation and process innovation, summarize the causes of problems and solutions in a timely manner, find out the root causes and grasp the essential problems. When the problems of the same root causes occur, respond quickly, and improve the efficiency of product innovation and innovation performance by shortening the time to solve the problems of product this study and development, new product production and market launch.

(2) The enterprise conducts risk preview and simulation audit once a year. In the process of new product design and development, production, sales and after-sales, we can simulate the possible quality problems and organize the memory. After the product is put into the market, according to the organization memory, solve similar problems quickly, reduce the risk and increase the innovation performance of the enterprise.

(3) Actively learn from the risk response system of other enterprises in the same industry for product, technology and organizational innovation, vaccinate, and increase the content of organizational quality memory. When the same or similar innovation problems occur, directly learn from the content of organizational quality memory, and deal with relevant pathogens. On the one hand, it can reduce the passive influence of the unknown innovation performance threat, on the other hand, it can prevent the trouble in advance.

This study uses fsQCA analysis method to carry out empirical analysis the impact of organizational quality specific immune on innovation performance from the perspective of organization specific immunity, which provides new ideas and combination methods for the study of innovation performance. At the same time, from the perspective of organization quality specific immune, it can obtain the path to promote innovation performance, which provides theoretical reference for enterprises to enhance innovation performance. Although this study extends the application scope and usage mode of fsQCA to study on innovation performance from a new perspective, it just aims at the impact of organizational quality monitoring, organizational quality defense and organizational quality memory on innovation performance under organizational quality specific immune. Although it involves the evaluation indicators under organizational quality monitoring, defense and memory, it has no impact on the evaluation indicators and innovation performance. The problems are required to be more perfect and sufficient in the future study. 


\title{
Acknowledgements
}

\author{
This research is funded by National Social Science Fund Project (17CGL020).
}

\section{References}

[1] Yihua W, Ping L, Bo X, Zhenning Y, Xiaoyang S, Debin D, Zhicheng S. and Xingguo D. (2006) The Study on Organization Immunity. Science of Science and Management of S. \& T., 27(6), 135-141.

[2] Liping S, Qiang L, Kangjun W, ZeWen D. (2013) Function Mechanisms of Organizational Quality Specific Immunity Elements Consistency on Quality Performance-Empirical Analysis Based on PP, Fit and Hierarchy Regression Analysis Method. Industrial Engineering and Management, 18 (3), 84-91.

[3] LiPing S, Qiang L, Yanan J, XinQi Y. (2015) Quality Performance Upgrading Paths Optimization Based on Projection Pursuit,RAGA,NK and GERT: Explaining Framework of Setting Organizational Quality Specific Immunity and Product Life Cycle as Main Logic. Operations Research and Management Science, 24(4), $188-97$.

[4] LiPing S, Qiang L, Shulin T. (2012) Quality Perfomance Upgrading Paths Based on Organizational Specific Immunity Perspective: Empirical Analysis of Projection Pursuit and Forced Method. Nankai Management Review, 15(6), 123-134.

[5] Heng C, Ruishu X, Yifu L. (2014) Research on Distributed Innovation, Specific Immune and Firm Growth Performance. Science \& Technology Progress and Policy, 31(12), 98-104.

[6] Xia Y. (2017) Research on the Current Situation of Technological Innovation Risk Management in Automobile Manufacturing Enterprises in China. Economic Research Guide, (34), 16-17.

[7] Wen Z, Na W. (2017) Research on Performance Improvement Path of Chinese Returnees Enterprises Considering Ambidextrous Network: The Fuzzy-Set Qualitative Comparative Analysis. Science of Science and Management of S.\& T., 38(5), 128-139.

[8] Ling L, Shanshan L, Shuqian Z. (2017) A Summary of Research on Enterprise Innovation Performance Index System. New West, (24), 64.

[9] Wei L. (2015) The Reviews and Enlightenment on the Relevance of Marketing Capabilities with Innovation Performance. Science and Technology Management Research, (5), 140-143.

[10] Xianjun L, Ling Z, Jinglun W. and Wei W. (2016) Impact of Open Innovation and Absorptive Capacity on Innovation Performance: An Empirical Analysis of China's Auto Firms. Science Research Management, 36(1), 4552.

[11] Yuxiao W. (2018) The Influence Mechanism of Multi-dimensional Proximity and Relationship Regulation on Enterprise Innovation Performance in Industry-University-Research Cooperation. Management and Administration, (2), 48-51.

[12] Hui F, Bin H, Qian Z. (2017) Research Review on the Influential Mechanism of Leadership on Creativity and Innovation Performance. East China Economic Management, 31(12), 60-66.

[13] Meng W. (2015) The Role of “Immune System" Theory in Reshaping Corporate Internal Audit Image. Times Finance, (9), 142.

[14] Xiangwu P, Nan W. (2015) Research on Principles and Ability Improving Ways of Immune Response of Enterprises Quality Management. Journal of Chongqing Jiaotong University (Social Sciences Edition), 15 (4), $57-$ 60.

[15] Nan W, Quanxi L. (2015) Empirical Study on Influencing Factors of Enterprise Risk Immune Ability under Immune Recognition Mechanism. Social Science Front, (2), 267-270.

[16] Ping L, Yihua W. (2015) Study on the Behavior and Mechanism of Organizational Immunology. Chinese Journal of Management, 6(5), 607-614.

[17] Tao J, Wei X. (2017) Research on Multilayered Distributed Organization Immune Response Model: An Integrated Perspective. Scientific Management Research, (14), 239-244.

[18] Yongheng X, Yu Z, Zhipeng Z. and Xuetao G. (2018) “Nerve and Immune System” in Enterprises. Manager, (282), 54-59.

[19] Hongyan Z, Shuangxi Y, Chang Y. (2015) Phase Evolution of Absorptive Capacity and Firm Innovation Performance: Empirical Analysis Based on New and High-tech Industries in Shanghai. Foreign Economics \& Management, 37(2), 3-17.

[20] Hongtao Y, Pingxiao Y. (2015) Study on the Influence of Openness, Relational Network and Knowledge Sharing on Innovation Performance of Enterprises. Industrial Engineering and Management, (2), 68-73.

[21] Baiyin Y, Ang G. (2013) Identifying Effective Approaches to Innovation Management and Innovative Performance. Science Research Management, 34(3), 41-49. 
[22] Daft R L. (1978) A Dual-Core Model of Organizational Innovation. The Academy of Management Journal, 21(2), 193-210.

[23] Damanpour F. (1991) Organizational Innovation: A Meta-Analysis of Effects of Determinants and Moderators. Academy of Management Journal, 34(3), 555-590.

[24] Gopalakrishnan S, Damanpour F. (1997) A Review of Innovation Research in Economics, Sociology and Technology Management. Omega, 25(1), 15-28.

[25] Hongmei Z. (2017) Research on the Influence of Government Support on the Innovation Performance of Manufacturing Enterprises From the Perspective of Open Innovation. Zhejiang Industrial and Commercial University.

[26] Quanxi L, Panshi S, Fenghua J. (2010) Research on Supply Chain Quality Management Model Based on the Perspectives of Immunity. Commercial Research, (7), 72-76.

[27] Hui X, Chunli J, Li J, Bin Z. and Xin J. (2011) Research on the Mechanism of Risk Response of Technology- SMEs Based on the Organizational Immunization Perspective. Management World, (2), 142-154.

[28] Ping L. (2011) An Empirical Study of the Influence Mechanism of Organizational Immune Behavior on Organizational Performance. Science and Science and Technology Management, 32 (7), 15-23.

[29] Ping L, Yihua W. (2009) Organizational Immune Behavior and Research Mechanism. Journal of Management, 6 (5), 607-614.

[30] Walsh J P, Ungson G R. (1991) Organizational Memory. Academy of Management Review, 16(1), 57-91.

[31] Jianbo Z. (2013) The Mechanism of the Impact of Organizational Cognition on Immune Behavior and Organizational Health - A Case Study of A Enterprise. Economic Management, 35(12), 54-64.

[32] Qiang L, LiPing S, Wei C, Yi S. (2016) Identification of Influence Factors of Team Quality Defect Management and the Extraction of Micro and Macro Fuzzy Rules Based on the SYT-FR-CA: Theoretical Framework Based on the Leading Logic of Medical Immunity and Medical Evidence. Industrial Engineering and Management, 21(3), 110-117.

[33] Ping L, Yihua W. (2008) Research on Enterprise Adaptability Based on Organizational Immune Perspective. Scientific Research Management, 29 (1), 164-171. 